\title{
A comparison of external and endoscopic endonasal dacryocystorhinostomy for acquired nasolacrimal duct obstruction
}

This article was published in the following Dove Press journal:

Clinical Ophthalmology

I2 July 20 I I

Number of times this article has been viewed

R Karim

R Ghabrial

TF Lynch

B Tang

School of Public Health, Faculty of Medicine, University of Sydney, Sydney, Australia
Correspondence: R Karim

I53-I73 Marylebone Road, London,

NWI 5QH, UK

Tel +442033I2 6666

Email rushmiak@gmail.com
Purpose: To compare success rates of external dacryocystorhinostomy (DCR) and endoscopic endonasal DCR for acquired nasolacrimal duct obstruction (NLDO).

Design: Historical cohort study.

Participants: 100 patients who underwent external DCR and 105 patients who underwent endoscopic endonasal DCR.

Methods: A retrospective review of medical records of patients with acquired NLDO who underwent DCR from 2004-2010 was performed. Data regarding the lacrimal drainage system, eye examination, surgical outcomes, patient symptom control, and postoperative care were analyzed.

Main outcome measures: Surgical success was defined by patient's resolution of symptoms with patency on irrigation. Surgical failure was defined as no symptomatic reduction in epiphora and/or an inability to irrigate the lacrimal system postoperatively.

Results: A total of 205 patients underwent surgeries for acquired NLDO. The average age was 69 years, and $62.4 \%$ of subjects were female. Pooled results showed that both surgical approaches had similar success rates (endoscopic endonasal DCR $82.4 \%$ versus external DCR $81.6 \% ; P=0.895)$. Complication rates were low in both types of surgery. This included three patients with postoperative hemorrhage (two who had endonasal DCR surgery and one having external DCR surgery). This resolved with conservative treatment. Postoperative problems with lacrimal patency (including canalicular obstruction) occurred to $6.8 \%$ of endoscopic patients and $9 \%$ of those with the external DCR surgery. Of the 14 patients who had their silicone tubes fall out before the 2-month assessment, 10 were classified as failures (71\%), in contrast to only a failure rate of $13.9 \%$ of those whose tubes were present for the recommended time. This difference was statistically significant $(P<0.01)$.

Conclusion: The success rate of DCR for acquired NLDO in our group of patients was high overall with a low complication rate between the two types of surgery. There was no statistically significant difference between endoscopic and external DCR. Endoscopic surgery may have a benefit of preserving the lacrimal pump system and leaving no surgical scar. Patient preference and availability of each service should direct management. Hence endoscopic endonasal DCR surgery should be considered for primary treatment of nasolacrimal duct obstruction.

Keywords: lacrimal sac, postoperative, irrigation, epiphora

\section{Introduction}

Standard treatment for nasolacrimal duct obstruction has been dacryocystorhinostomy (DCR) surgery. The external approach is performed through a cutaneous incision to access the lacrimal sac. The procedure gained popularity due to its efficacy and relatively low complication rates. Endoscopic endonasal DCR has gathered momentum 
with direct visualization under endoscopic guidance. Caldwell first introduced the endonasal approach for lacrimal surgery in 1893. However endoscopic endonasal DCR has only become recently employed with new endoscopy instruments and technique. ${ }^{1}$ This approach avoids an external scar and neurovascular disruption along the tract exposing the lacrimal sac.

The reported success rates of both procedures range from $63 \%$ to $97 \% .^{2-4}$ The wide range of success is likely due to surgical variability, patient demographics, and lack of standardized outcome measures in the medical literature. The purpose of the current study was to evaluate both the functional/anatomic success as well as symptom control for endoscopic endonasal and external DCR surgeries performed at two specialized centers.

\section{Methods}

Medical records were reviewed in all patients who underwent surgery for acquired nasolacrimal duct obstruction (NLDO) from January 2004 to May 2010. The study was carried out in accordance with the ethical guidelines of the Declaration of Helsinki with institutional ethical approval. Data was collected in a spreadsheet with a standard collection template used for both types of operations.

A diagnosis of NLDO was made from ophthalmic examination and/or radiological findings. All patients included had symptoms of epiphora. Documented obstruction on syringing and probing or obstruction on lacrimal scintigraphy were used in the diagnosis of NLDO.

Patients with previous DCR surgery to the same eye were excluded from the study. Refer to Table 1 for selection criteria for nasolacrimal duct obstruction.

Surgery choice of external or endoscopic endonasal DCR was based on hospital or day surgery attended. All operations at the two eye centers were performed by one of the authors (RG). All patients who had the external DCR surgery held private health insurance. The endonasal endoscopic DCRs were performed at a public hospital. This is a weakness of the study.

\section{Table I Selection criteria for cases with NLDO}

\begin{tabular}{ll}
\hline Inclusion & Exclusion \\
\hline Epiphora & Previous DCR to same eye \\
Evidence of obstruction & Congenital NLDO \\
on probing and irrigation & \\
Fluorescein dye disappearance test & \\
Obstruction on lacrimal scintigraphy & Age under 16 years \\
\hline
\end{tabular}

Abbreviations: DCR, dacryocystorhinostomy; NLDO, nasolacrimal duct obstruction.
Patients underwent ophthalmic examinations including irrigation of the nasolacrimal drainage systems, fluorescein dye disappearance test, and intranasal examination. All patients had tubes inserted intra-operatively.

Standard external approach was used. Endoscopic endonasal DCR surgery consisted of adequate lacrimal sac exposure and creation of a large marsupialized lacrimal sac, covering the exposed bone with preserved nasal mucosal flaps.

Postoperatively, the silicone tube was removed after 1-2 months. In 14 patients, the tubes fell out early, and four patients had their tubes in situ for more than 4 months. Irrigation of the nasolacrimal systems and fluorescein dye disappearance test was performed at postoperative follow-up appointments in all patients.

Postoperatively, all patients were assessed within 1 month of surgery. Patient follow-up included 2 months follow-up for tube assessment and subsequent 4-12-month follow-up for progress and symptom surveillance. During postoperative visits, patients were asked about symptomatic resolution of epiphora and assessed with patency on irrigation, fluroscein dye disappearance test, and intranasal examination. Postoperative complications were also noted at each visit. All patients were followed up for at least 6 months (range 6-24 months).

Results were defined by patient's resolution of symptoms with patency on irrigation and a positive fluorescein dye disappearance test. Patients' resolution of symptoms were stratified into four categories during data collection. These were: 1) no epiphora and complete resolution of symptoms; 2) improved epiphora with associated patient satisfaction, with no further follow-up required; 3) continued epiphora with no improvement; and 4) revision DCR surgery required with or without Jones tubes. Only patients with patency on irrigation of the lacrimal system and a negative fluorescein dye disappearance test postoperatively could be classified into categories 1 and 2 .

Outcome measures were pooled in order to determine success or failure. Patients who were categorized 1 and 2 with patency on irrigation were defined as a successful outcome. Patients were also categorized as surgical failure if they experienced any postoperative episode of dacryocystitis. Inability to irrigate the lacrimal system postoperatively, nasal endoscopy with scarring at the intranasal osteotomy, and/or no visualization of fluorescein dye was also classified as a surgical failure. It can be noted that patients with improved or resolved symptoms but with postoperative obstruction on irrigation were still classified as surgical failure. Refer to Table 2 for outcome measures. 
Table 2 Outcome measures for cases post dacryocystorhinostomy surgery

\begin{tabular}{ll}
\hline Success & Failure \\
\hline Patency on probing and irrigation & $\begin{array}{l}\text { Obstruction on probing and } \\
\text { irrigation }\end{array}$ \\
Resolution of symptoms & Ostial scarring \\
Improvement of symptoms & No visualization of fluorescein \\
& in dye disappearance test \\
& Persistent symptoms \\
& Requiring revision or adjuvant \\
& intervention \\
\hline
\end{tabular}

Patient demographic data was collected, including age, gender, date of birth, ethic origin, and language. Refer to Table 3 for baseline characteristics stratified by endonasal endoscopic and external DCR surgery.

\section{Surgical technique}

\section{Endoscopic endonasal DCR}

Endoscopic endonasal DCR was performed under general anesthesia. After vasoconstriction of the nasal cavity by neurosurgical pledges soaked in cocaine, the head of the middle turbinate and the mucosa surrounding the lacrimal sac are infiltrated with a (lignocaine and lidocaine combination) local anesthetic. The dose of local anesthetic was not recorded in the data template. A surgical incision is made at the lateral nasal wall, anterior superior to the insertion of the middle turbinate. The posterior mucosal flap is elevated off the maxillary bone and incision made until the sac is exposed. Metallic lacrimal probes are passed medially through both canaliculi so as to tent the sac lumen. By preserving the nasal submucosal injection in the presumed lacrimal fossa during opening of the sac, marsupialization can occur to appose the nasal mucosa. A silicone bicanalicular tube is then positioned and tied. All patients were given postoperative chloramphenicol and prednisone drops to the affected eye four times a day for a month as well as oral cephalosporin. Medication variation was only considered if the patient had a known allergy. Patients are encouraged to wash using nasal rinse or sprays to prevent crust formation.

\section{External}

External DCR was performed under local anesthetic. Some patients were sedated for the duration of the procedure. A straight incision is made medially to the angular vein at the level of the medial canthal ligament. The wound is opened with traction sutures for adequate exposure of the anterior lacrimal crest. An osteotomy is created and lacrimal sac and musoca opened to form anterior and posterior flaps. Probing ensures site of obstruction is localized, then flaps sutured with $6 / 0$ vicryls sutures. A silicon tube is inserted and tied. The wound is closed and skin is sutured using fine sutures for cosmetic effect. All patients were given chloramphenical and prednisilone eye drops four times a day for a month postoperatively. The tubes were kept in situ for a minimum duration of 2 months before removal.

\section{Statistical analysis}

Independent-samples $t$-test and $\chi^{2}$-nonparametric analysis were used to compare numerical variables and proportions, respectively, between successful and failed cases and between endoscopic and external DCRs. Significance testing was carried out on patient demographics, ocular history, comorbidities and symptoms, peri and postoperative outcomes and follow up. Outcomes measures were pooled with assessment of statistical significance. SPSS program was used for the statistical analysis.

\section{Results}

A total of 205 patients were included in the study (128 females and 77 males), with a mean age of 69 years. Demographics between the two surgical groups were similar. There was no statistically significant difference in comorbidities, previous sinus disease or surgery, ocular history, or presenting symptoms. There was a statistically significant difference in the ethnic origin, with more Caucasians in the external DCR group than the endoscopic endonasal group (see Table 3).

Multivariate analysis was not performed, as the majority of the groups' characteristics were statistically similar apart from intervention.

The operation was classified as successful by the objective demonstration of a patent nasolacrimal system through irrigation. Patency was achieved in $96(93.2 \%)$ of 103 patients for the endonasal DCR and $83(91.2 \%)$ of 91 patients for external DCR surgery (refer to Table 4$)$. The difference was not statistically significant $(P=0.604)$.

Anatomical patency and symptom relief (6-24 months postoperatively) was achieved in $84(82.4 \%)$ of 102 patients in the endonasal DCR group and $80(81.6 \%)$ of 98 patients in the external DCR group (Table 4). This difference was not statistically significant $(P=0.895)$. Refer to Table 5 for results of success stratified by DCR surgery, endonasal and external.

The complication incidence was low and similar in both operations. Three patients had postoperative hemorrhage 
Table 3 Demographics of endoscopic endonasal and external dacryocystorhinostomy groups

\begin{tabular}{|c|c|c|c|c|c|}
\hline & Categorized & Total (205) & Endoscopic (105) & External $(100)$ & Overall $P$ value \\
\hline Age, mean (SD) & & $68.89(15.022)$ & $66.77(17.432)$ & 70.34 (I2.829) & NS \\
\hline Female sex (\%) & & 128 & $68(64.8)$ & $60(60)$ & 0.482 \\
\hline \multirow[t]{6}{*}{ Ethnicity (\%) } & Caucasian & I35 (7I.4) & $58(59.2)$ & $77(84.6)$ & \\
\hline & Oriental & $20(10.6)$ & $12(12.2)$ & $8(8.8)$ & \\
\hline & Indian & $3(1.6)$ & $3(3.1)$ & $0(0)$ & \\
\hline & Subcontinent & & & & \\
\hline & European & $30(15.9)$ & $24(24.5)$ & $6(6.6)$ & \\
\hline & African & $\mathrm{I}(0.5)$ & $I(I)$ & $0(0)$ & 0.001 \\
\hline NESB & & $29(14.3)$ & $20(19.2)$ & $9(9.1)$ & 0.039 \\
\hline Previous sinus surgery & & $6(3)$ & $2(1.9)$ & $4(4.2)$ & 0.353 \\
\hline History of ocular trauma & & $7(3.5)$ & $6(5.7)$ & $I(I)$ & 0.069 \\
\hline \multicolumn{6}{|l|}{ with either NLD obstruction } \\
\hline \multicolumn{6}{|l|}{ or canalicular laceration } \\
\hline Comorbidities (yes) & & $125(61.6)$ & $66(62.9)$ & $59(60.2)$ & 0.698 \\
\hline HT & & $88(44)$ & $47(44.8)$ & $4 \mathrm{I}(43.2)$ & 0.819 \\
\hline DM & & $23(11.5)$ & $17(16.2)$ & $6(6.3)$ & 0.029 \\
\hline \multirow[t]{3}{*}{ Smoking } & No & $170(85)$ & $88(83.8)$ & $82(86.3)$ & \\
\hline & Yes & $22(11)$ & $9(8.6)$ & $13(13.7)$ & \\
\hline & Ex & $8(4)$ & $8(7.6)$ & $0(0)$ & 0.140 \\
\hline \multirow[t]{8}{*}{ Ocular history } & No & $90(44.3)$ & $48(46.2)$ & $42(42.4)$ & \\
\hline & $\begin{array}{l}\text { Previous cataract } \\
\text { surgery }\end{array}$ & $16(7.9)$ & $9(8.7)$ & $7(7.1)$ & \\
\hline & Glaucoma & $9(4.4)$ & $I(I)$ & $8(8.1)$ & \\
\hline & Corneal disease & $\mathrm{I}(0.5)$ & $0(0)$ & $I(I)$ & \\
\hline & Ocular plastic & $38(18.7)$ & $22(21.2)$ & $16(16.2)$ & \\
\hline & Retinal & $9(4.4)$ & $3(2.9)$ & $6(6.1)$ & \\
\hline & Other & $8(3.9)$ & $2(1.9)$ & $6(6.1)$ & \\
\hline & $\begin{array}{l}\text { More than two } \\
\text { ocular conditions }\end{array}$ & $32(15.8)$ & $19(18.3)$ & $13(13.1)$ & 0.099 \\
\hline Epiphora & & $204(100)$ & $104(100)$ & $100(100)$ & Constant \\
\hline Red eyes & & $35(17.2)$ & $14(13.6)$ & $2 I(2 I)$ & 0.162 \\
\hline Blepharitis & & $38(18.7)$ & $21(20.4)$ & $17(17)$ & 0.536 \\
\hline Inflammatory eye disease & & $2(1)$ & $2(1.9)$ & $0(0)$ & 0.161 \\
\hline Itchy eyes & & $42(20.7)$ & $17(16.5)$ & $25(25)$ & 0.135 \\
\hline Dacrocystitis & & $35(17.5)$ & $21(20.6)$ & $14(14.3)$ & $0.24 I$ \\
\hline Conjunctivitis history & & $17(8.4)$ & $13(12.6)$ & $4(4)$ & \\
\hline Antibiotic use & & $57(27.9)$ & $28(26.9)$ & $29(29)$ & \\
\hline \multicolumn{5}{|l|}{ than 3 months } & 0.008 \\
\hline $\begin{array}{l}\text { Use of chloramphenicol } \\
\text { drops }\end{array}$ & & $84(41.4)$ & 39 (37.9) & $45(45)$ & 0.302 \\
\hline Glasses/contacts & & $143(74.1)$ & $66(68)$ & $77(80.2)$ & 0.054 \\
\hline \multicolumn{6}{|l|}{ Anticoagulation } \\
\hline $\begin{array}{l}\text { Past treatment duration } \\
\text { months (SD) }\end{array}$ & & $32.56(25.34)$ & $28.2(24.9)$ & $37.18(25.03)$ & NS \\
\hline Obstruction viewed & & $199(100)$ & $204(100)$ & $95(100)$ & Constant \\
\hline
\end{tabular}

Abbreviations: DM, diabetes mellitus; HT, hypertension; NESB, non-English speaking background; NLD, nasolacrimal duct; NS, not significant; SD, standard deviation.

(two who had endonasal DCR surgery and one having external DCR surgery). Postoperative hemorrhage was either wound hemorrhage or epistaxis. All of these patients were treated conservatively, including nasal spray and/or packing. Hemostasis was achieved with no secondary hemorrhage resulting in surgical intervention. Canalicular obstruction was documented in six cases, with three in each of the surgical groups. There was no documented orbital and subcutaneous emphysema, conjunctival fistula formation, retrobulbar hemorrhage, medical rectus paresis, orbital fat herniation, or nasal mucosal synechiae formation. See Table 6 for postoperative results and complications stratified by DCR surgery, endoscopic endonasal and external.

Fourteen patients who underwent DCR surgery had tubes that fell out before the 2-month assessment, of which six were in the endonasal group and eight in the external group. There 
Table 4 Summary of surgical success

\begin{tabular}{llll}
\hline $\begin{array}{l}\text { Surgical } \\
\text { results }\end{array}$ & Endonasal & External & $\begin{array}{l}\text { Statistical } \\
\text { significance }\end{array}$ \\
\hline Anatomical patency & $96 / 103(93.2 \%)$ & $83 / 91(91.2 \%)$ & $P=0.604$ \\
$\begin{array}{l}\text { Anatomical patency } \\
\text { and symptom relief }\end{array}$ & $84 / 102(82.4 \%)$ & $80 / 98(81.6 \%)$ & $P=0.895$ \\
\hline
\end{tabular}

was no statistical significance between the external DCR group and the endoscopic endonasal group $(P=0.44)$. Of these patients, 10 had persistent symptoms or surgical failure (71\%). Of the 186 patients who had their tubes in situ for the recommended time ( 2 months), 26 had persistent symptoms or surgical failure (13.9\%). This difference was statistically significant $(P<0.01)$.

No endonasal DCR operations needed conversion to external DCR surgery. A biopsy was required for four endonasal surgeries due to detection of polyps or suspicious lesions. One patient was found to have a nasal polyp, with three other biopsy results reporting inflammatory or keratotic lesion. The exact anatomical location of the biopsies were unknown.

Twenty-one patients were candidates for revision surgery: $9(8.8 \%)$ of 104 patients in the endonasal group, and 12 $(12.2 \%)$ of 98 patients in the external group. This difference was not statistically significant. The main reasons for revision surgery were persistent or worse symptoms. Endoscopic revision surgery was undertaken instead of a revision external DCR, due to surgeon and patient preference. Seven patients with previous external DCR underwent revision endonasal DCR. Patency and symptom resolution was achieved in four cases. Two patients had patency on probing and irrigation, but persistent symptoms. One patient had repeat DCR surgery, with a total of three external and endonasal DCR to the same eye with continued persisting symptoms. Five patients who had previous initial endonasal DCR underwent revision endonasal DCR. Four out of five of these patients had patency on irrigation, but only two patients had resolution of symptoms, with three patients experiencing persistent epiphora. The discrepancy between anatomical patency and resolution of symptoms may be due to the lacrimal paradox outlined in the discussion..$^{5-7}$

\section{Discussion}

External DCR surgery at the turn of the century was regarded as the gold standard in treatment for nasolacrimal duct obstruction. The case for this procedure lies in its predictability of success and direct visualization of the anatomy compared with a nasoendoscope. However, the procedure leaves a cutaneous scar and the potential for injury to medial canthal structures, cerebrospinal fluid rhinorrhea, and functional interference with the physiological action of the lacrimal pump. ${ }^{8}$

Over the last decade, however, endoscopic DCR has shown equally promising results for long-term success in nasolacrimal duct obstruction with the benefits of minimal invasive surgery. Endoscopic DCR allows direct inspection of the lacrimal sac for underlying pathology. With an understanding of the intranasal anatomy, assessment and treatment of obstruction can be a routine procedure. The assessment of failures can also be viewed endoscopically. This allows recognised mistakes to be immediately revised at the time of surgery. Intranasal biopsy of suspicious mucosa can be taken for further assessment. The option of converting an endoscopic DCR to external approach during initial surgery

Table 5 Results of success stratified by DCR surgery endoscopic endonasal and external

\begin{tabular}{|c|c|c|c|c|c|}
\hline Results & & Total & Endonasal DCR & External DCR & Overall $P$ value \\
\hline Lacrimal patency & & $179(92.3)$ & $96(93.2)$ & $83(91.2)$ & 0.604 \\
\hline Symptoms 2 weeks & Resolution & $56(27.7)$ & $27(26.2)$ & $29(29.3)$ & \\
\hline \multicolumn{6}{|l|}{ post DCR } \\
\hline & Persistent & $15(7.4)$ & $8(7.8)$ & $7(7.1)$ & \\
\hline & Symptoms worse & $3(1.5)$ & $3(2.9)$ & $0(0)$ & 0.270 \\
\hline \multirow[t]{4}{*}{ Follow up months } & Resolution & $145(72.5)$ & $76(74.5)$ & $69(70.4)$ & \\
\hline & Improved & $19(9.5)$ & $8(7.8)$ & II (II.2) & \\
\hline & Persistent & $15(7.5)$ & $9(8.8)$ & $6(6.1)$ & \\
\hline & Revision surgery & $21(10.5)$ & $9(8.8)$ & $12(12.2)$ & 0.566 \\
\hline \multirow[t]{2}{*}{$\begin{array}{l}\text { Pooled results of final } \\
\text { follow up }\end{array}$} & $\begin{array}{l}\text { Resolution of symptoms or } \\
\text { improvement from baseline }\end{array}$ & $164(82)$ & $84(82.4)$ & $80(81.6)$ & 0.895 \\
\hline & $\begin{array}{l}\text { Persistent Symptoms and or } \\
\text { revision surgery }\end{array}$ & $36(18)$ & $18(17.6)$ & $18(18.4)$ & 0.895 \\
\hline $\begin{array}{l}\text { Total number of eye } \\
\text { clinic visits (SD) }\end{array}$ & & $4.72(1.602)$ & $5.06(2.044)$ & $4.38(0.844)$ & NS \\
\hline
\end{tabular}

Abbreviations: DCR, dacryocystorhinostomy; SD, standard deviation. 
Table 6 Post operative results and complications stratified by dacryocystorhinostomy surgery, endoscopic endonasal and external

\begin{tabular}{|c|c|c|c|c|}
\hline & $\begin{array}{l}\text { Total (205) } \\
\text { Cases (\%) }\end{array}$ & $\begin{array}{l}\text { Endoscopic (105) } \\
\text { Cases (\%) }\end{array}$ & $\begin{array}{l}\text { External }(100) \\
\text { Cases }(\%)\end{array}$ & $\begin{array}{l}\text { Overall } P \text { value } \\
\text { Cases }(\%)\end{array}$ \\
\hline \multicolumn{5}{|l|}{ Postoperative results } \\
\hline Intra-operative complications & $8(4.3)$ & $5(4.8)$ & $3(3.7)$ & 0.701 \\
\hline Change in routine treatment & $26(13.2)$ & II (I0.8) & $15(15.8)$ & 0.300 \\
\hline Lacrimal irrigation no patency & $15(7.7)$ & $7(6.8)$ & $8(8.8)$ & 0.604 \\
\hline Tubes fallen out & $14(7.3)$ & $6(5.9)$ & $8(8.8)$ & 0.437 \\
\hline Adjunct surgery & $17(8.7)$ & II (I0.9) & $6(6.3)$ & 0.255 \\
\hline $\begin{array}{l}\text { Associated conditions example } \\
\text { sinus disease diagnosed }\end{array}$ & $24(12.2)$ & $20(19.6)$ & $4(4.2)$ & 0.001 \\
\hline $\begin{array}{l}\text { Referral for other pathology } \\
\text { or ocular conditions }\end{array}$ & $30(15.2)$ & $21(20.6)$ & $9(9.5)$ & 0.030 \\
\hline \multicolumn{5}{|l|}{ Postoperative complications } \\
\hline Postoperative hemorrhage & $3(1.5)$ & $2(2.0)$ & $\mathrm{I}(\mathrm{I} .0)$ & 0.597 \\
\hline Punctal erosion & 0 & 0 & 0 & \\
\hline Canalicular obstruction & $6(3.0)$ & $3(2.9)$ & $3(3.2)$ & 0.930 \\
\hline
\end{tabular}

is always available for difficult cases or those with lacrimal sac tumours. ${ }^{9}$

The endoscopic approach has a reduced risk of interfering with the medial canthal tendon and physiology of the lacrimal pump mechanism. There is the advantage of no external scar, providing a desired cosmetic effect for patients. ${ }^{4}$ More importantly endoscopic endonasal DCR surgery has been shown to have earlier postoperative recovery time. ${ }^{10,11}$ Additionally, the Watters et al paper on long-term results for endoscopic DCR surgery showed lower rates of air regurgitation while nose blowing. ${ }^{12}$

Both surgical procedures have minimal rates of hemorrhage, but there is a lower to nil risk of cerebrospinal fluid rhinorrhea in endoscopic endonasal surgery. ${ }^{6,13}$ Dacryocystitis is not a direct contraindication to the endoscopic surgery, and patients with chronic dacryocystitis can be treated with the endoscopic technique. ${ }^{13}$

The endoscopic approach allows diagnosis and management of associated conditions. In our series, 20 patients who had endoscopic endonasal surgery were identified or treated with an associated condition, including septal deviation, sinus disease, and dacryocystitis. Only four patients were identified with an associated condition in the external DCR group. This difference was statistically significant $(P=0.001)$. Hence, patients with a concomitant nasal and paranasal disorder that may contribute to the nasolacrimal obstruction can be diagnosed and treated simultaneously if the endoscopic endonasal procedure is performed. ${ }^{14}$

Complications of endoscopic endonasal DCR are low but can include re-stenosis of the opening, bleeding from the nasal cavity, orbital injury and corneal abrasion, or canaliculi erosion. ${ }^{15-17}$ A lacrimal sump syndrome and associated recurrent infections can occur if the lower portion of the bone surrounding the sac is removed inadequately. This can be avoided with a marsupialization technique used in our surgeries. Opening the sac inferior to the proximal nasolacrimal duct after bone removal can prevent this syndrome. ${ }^{13}$

Tsirbas and Wormald used a similar technique in endoscopic DCR to fully expose the lacrimal sac and marsupialize it into the lateral nasal wall with the nasal and lacrimal mucosa in apposition. They achieved high long-term success rates with this approach at $89 \% .^{18-20}$

Serious complications including orbital and subcutaneous emphysema, retrobulbar hemorrhage, medial rectus paresis, and orbital fat herniation ${ }^{15}$ are rare in the medical literature for both forms of DCR surgery. Of the 226 patients who underwent endoscopic endonasal DCR in the Sonkhya retrospective case series, only two patients had complications of orbital fat prolapse and lamina papyracea damage. Both had no sequele from this complication. ${ }^{13}$ We found no serious complications in our study, with only three patients with postoperative hemorrhage requiring conservative treatment. In a case series of 79 external DCRs, 14 patients had postoperative hemorrhage compared with 0 out of 51 patients in the endoscopic endonasal group. ${ }^{21}$ The latter group all had a general anesthetic where hypotension could be achieved, hence most likely resulting in the lower rates of bleeding.

Endoscopic DCRs in our case series were performed with general anesthetic. Local anesthetic techniques have been reported with safe results for patients. A prospective study of 26 endoscopic DCRs showed no anesthetic complications under local anesthetic. ${ }^{22}$ Both surgical procedures can be performed as day only cases. A case series of warfarinized patients undergoing endoscopic endonasal DCR found the 
treatment to be safe and efficacious for treatment of distal nasolacrimal obstruction. The anticoagulated patients were not required to stop their warfarin preoperatively. This increases the generalizability of the procedure to a broader patient pool. ${ }^{23}$ All nine surgeries were performed under local anesthetic. In this study, a statistically significant difference in the ethnic origin was noted, where there were more Caucasians in the external DCR group than the endoscopic endonasal group. This difference may be due to the external group having private health insurance and the endonasal procedure carried out on patients in a public hospital.

Surgical success was defined as both anatomical patency and symptom relief in our study, giving more conservative results. Anatomical patency and symptom control have varying results in both external and endoscopic surgery throughout the medical literature.

Geoff Rose describes the lacrimal paradox, where anatomical success may not correlate to success in control of symptoms and vice versa. He describes the signs and symptoms of drainage disorders to be either volume related or flow related. Volume-related backwash from the lacrimal sac in most cases can be treated with appropriate surgery. However, flow-related characteristics are largely due to limitation or tear conductance from the lateral canthus to the nose. Symptom relief of flow-related symptoms is not achievable in every patient, especially if there is hydraulic resistance of the canaliculi and nasolacrimal duct. ${ }^{6,7}$

A small lacrimal punctum can cause tearing and may require patients to undertake a 3 -snip punctoplasty. This, as well as ligament laxity of the eyelid and hypersecretion of the lacrimal gland, can also cause epiphora in patients with a patent functional nasolacrimal apparatus.

Endoscopic endonasal DCR has an established role in revision DCR surgery. Boush reported five successes in endoscopic revision in six primary endoscopic failures. ${ }^{24}$ In our study, five patients underwent revision endoscopic endonasal DCR, with four patients having patency on irrigation, and of those, two patients with complete resolution of symptoms. Seven patients with previous external DCR underwent revision endonasal DCR. Patency and symptom resolution was achieved in four cases. Ben Simons' case series of 22 revisions found similar results, with success in nine patients who failed the first procedure. ${ }^{15}$

It is difficult to compare success rate for primary surgery between external DCR and the endoscopic endonasal procedures as there are few comparative studies. Few studies have standard outcome measures, with some studies defining success as patency to irrigation with others concentrating on symptom resolution. Our study included both objective patency results and subjective patient symptom measurements. Evidence for endoscopic dacryocystorhinostomy appears to be comparable to the "gold standard" external approach, with success rates ranging from $78 \%$ to $97 \%$. Refer to Table 7. A weakness in our study was that one group of surgical patients held private insurance, whilst the other procedure patients were performed in the public hospital. The difference in demographics may have confounded the outcomes, although baseline characteristic data was gathered for both groups.

Our findings showed a high success rate of both endoscopic and external approach, with $92.3 \%$ of patients showing patency to irrigation and $82 \%$ showing improved or resolution of symptoms. There was no statistically significant difference between the two surgical approaches. The high predictability of external DCR in previous case series may in fact have been operator dependant rather than due to the surgery itself.

Endoscopic DCR are more expensive to run initially, with high equipment costs compared with general ophthalmology used in external DCR. ${ }^{2}$ However, with shorter surgical times and use of local anesthetic in a day-surgery setting, these costs can be absorbed over time. ${ }^{2,25}$ The procedure is technically involved and can initially be difficult to learn. Experience with persons highly skilled with endonasal surgery and endoscopic techniques is imperative, and this can incur higher training costs only in the short-term. ${ }^{10}$

A learning curve of the endoscopic procedure was demonstrated in several studies. Onerci stratified according to experience of the surgeon and found high success rates of up to $94 \%$ with experienced surgeons, compared with inexperienced surgeons with success rates of only $58 \%{ }^{26}$ This highlights the emphasis of DCR surgery to be performed by ophthalmologists with an understanding of intranasal anatomy, perhaps with initial training together with an ENT (ear, nose, and throat) surgeon.

Boush and Unlu found a strong relationship between silicone tube retention and success, which was mirrored in our study. ${ }^{24,27}$ Fourteen patients who underwent DCR surgery had tubes that fell out before the 2-month assessment. Of these patients, 10 had persistent symptoms or surgical failure, giving a failure rate of $71 \%$. This difference was statistically significant with patients whose tubes were in at the 2-month assessment, having a failure rate of $13.9 \%(P<0.01)$. For both external and endoscopic endonasal DCR surgery having the silicone tube in situ for the recommended time period is important to achieve surgical success. 


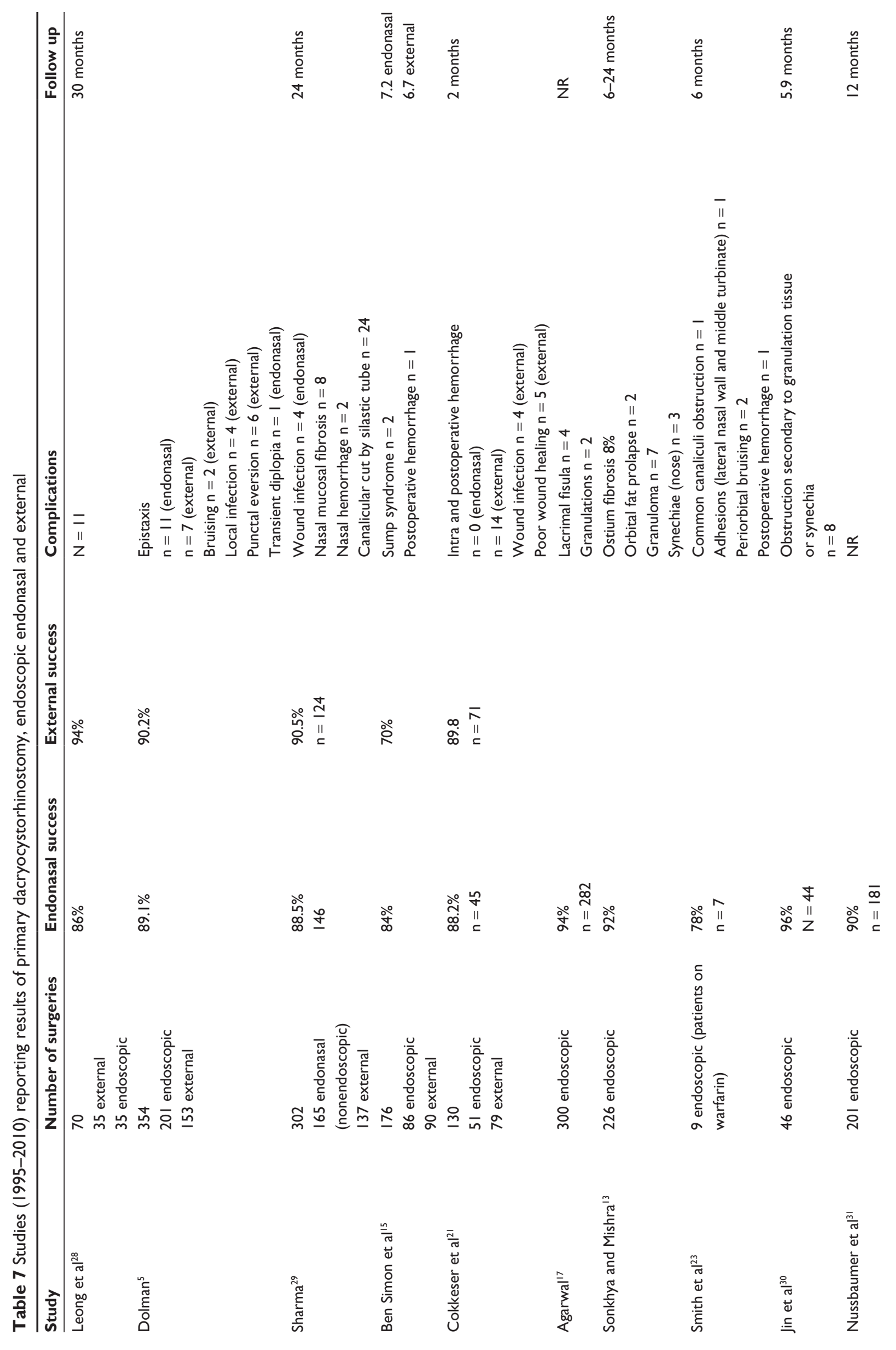




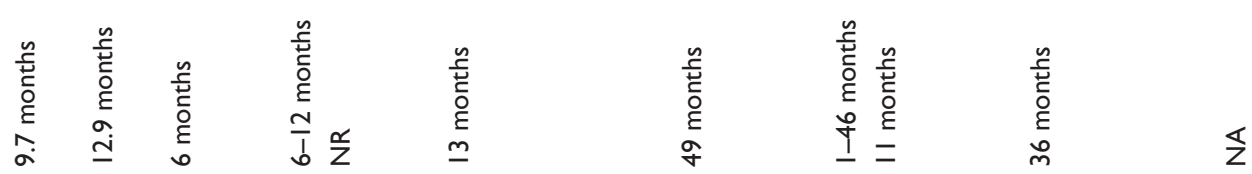
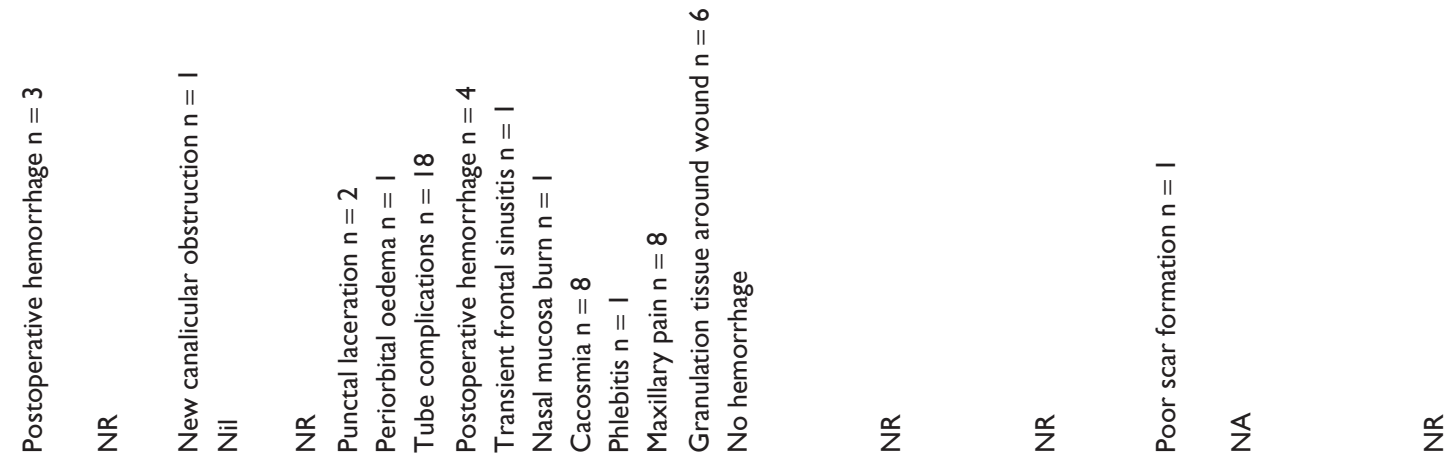

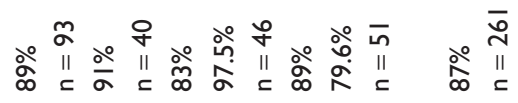
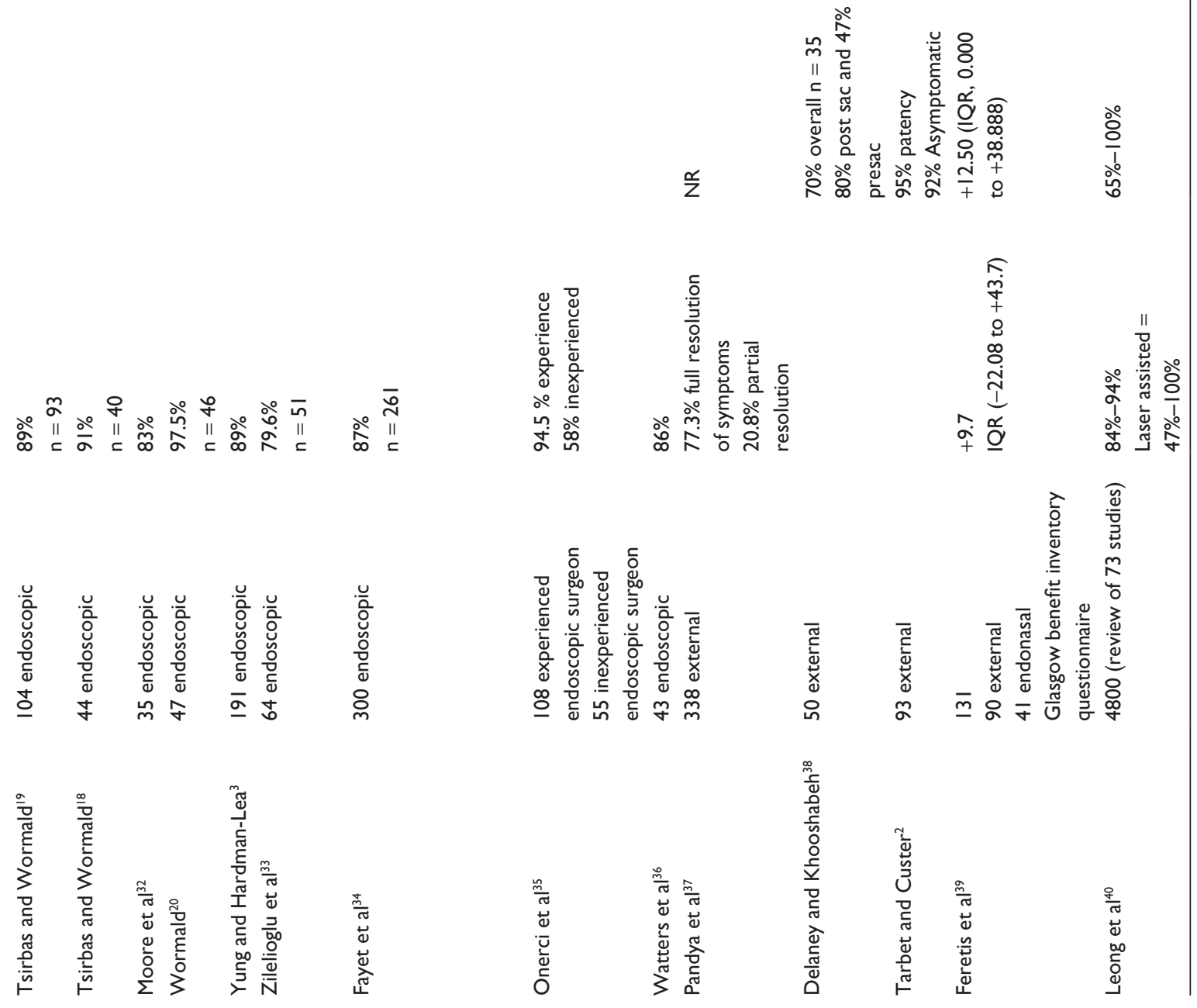


\section{Conclusion}

DCR is the treatment of choice for the treatment of nasolacrimal duct obstruction. All studies show similar results in regards to external versus endoscopic surgery.

Both operations have low complication rates. The advantage of endoscopic surgery is that it leaves no scar and preserves the lacrimal pump system, unlike external DCR. An understanding of intranasal anatomy, however, is required for endoscopic surgery, with appropriate endoscopic training.

Choice in regards to surgical techniques should depend on patient preference, with consideration given on the availability of resources amongst health care systems. The endoscopic endonasal approach was introduced in 1893 by Caldwell, ${ }^{1}$ but only over the last decade have we seen the predictable high success rates like that of external DCR.

Endoscopic DCR surgery with its discussed benefits warrants a place in the 21 st century as a contender for primary treatment of nasolacrimal duct obstruction.

\section{Acknowledgment}

The authors thank Mr Naser Ali at The Western Eye Hospital.

\section{Disclosure}

The authors report no conflicts of interest in this work.

\section{References}

1. Caldwell GW. Two new operations for obstruction of the nasal duct, with preservation of the canaliculi, and with an incidental description of a new lacrimal probe. Am J Ophthalmol. 1893;10:189-193.

2. Tarbet KJ, Custer PL. External dacryocystorhinostomy: surgical success, patient satisfaction, and economic cost. Ophthalmology. 1995;102: 1065-1070

3. Yung MW, Hardman-Lea S. Analysis of the results of surgical endoscopic.

4. Durvasula V, Gatland DJ. Endoscopic dacryocystorhinostomy:longterm results and evolution of surgical technique. J Laryngol Otol. 2004; 118:628-632.

5. Dolman PJ. Comparison of external dacryocystorhinostomy with nonlaser endonasal dacryocystorhinostomy. Ophthalmology. 2003;110(1): $78-84$.

6. Guthoff RF, Katowitz JA. Essentials in Ophthalmology: Oculoplastics and Orbit, The Apparent Paradox of "Success" in Lacrimal Drainage Surgery. 3rd ed. Berlin: Springer; 2005.

7. Rose GE. The lacrimal paradox: towards a greater understanding of success in lacrimal surgery. Ophthal Plast Reconstr Surg. 2004;20: 262-265.

8. Shun-Shin GA, Thurairajan G. External dacryocystorhinostomy - an end of an era? Br J Ophthalmol. 1997;81:716-717.

9. Zhou W, Zhou M, Li Z, Wang T. Endoscopic intranasal dacryocystorhinostomy in forty-five patients. Chin Med J (Engl). 1996;109:747-748.

10. Watters GWR, Whittet HB, Shun-shin GA, Milford CA. Endoscopic transnasal dacryocystorhinostomy - long-term results. Minim Invasive Ther Allied Technol. 1996;5:505-510.

11. Metson R. Endoscopic surgery for lacrimal obstruction. J Otolaryngol Head Neck Surg. 1991;104:473-479. 
12. Watters GWR, Whittet HB, Shun-Shin GA, Milford CA. Endoscopic transnasal dacryocystorhinostomy long term results. Min Invas Ther Allied Technol. 1996;5:505-510.

13. Sonkhya N, Mishra P. Endoscopic transnasal dacryocystorhinostomy with nasal mucosal and posterior lacrimal sac flap. J Laryngol Otol. 2009;123(3):320-326.

14. Royal Australasian College of Surgeons. New and Emerging Techniques - Surgical Rapid Review: Endoscopic Dacryocystorhinostomy. North Adelaide, Australia: Australian Safety and Efficacy Register of New Interventional Procedures - Surgical; 2003.

15. Ben Simon GJ, Joseph J, Lee S, Schwarcz RM, McCann JD, Goldberg RA. External versus endoscopic dacryocystorhinostomy for acquired nasolacrimal duct obstruction in a tertiary referral center. Ophthalmology. 2005;112:1463-1468.

16. Woog JJ, Kennedy RH, Custer PL, Kaltreider SA, Meyer DR, Camara JG. Endonasal dacryocystorhinostomy. Ophthalmology. 2001;108: 2369-2377.

17. Agarwal S. Endoscopic dacryocystorhinostomy for acquired nasolacrimal duct obstruction. J Laryngol Otol. 2009;123:1226-1228.

18. Tsirbas A, Wormald PJ. Endonasal dacryocystorhinostomy with mucosal flaps. Am J Ophthalmol. 2003;135:76-83.

19. Tsirbas A, Wormald PJ. Mechanical endonasal dacryocystorhinostomy with mucosal flaps. Br J Ophthalmol. 2003;87:43-47.

20. Wormald PJ. Powered endoscopic dacryocystorhinostomy. Laryngoscope. 2002;112:69-72.

21. Cokkeser Y, Evereklioglu C, Er H. Comparative externalversus endoscopic dacryocystorhinostomy: result in 115 patients (130 eyes) Otolaryngol Head Neck Surg. 2000;123:488-491.

22. Howden J, McCluskey P, O'Sullivan G, Ghabrial R. Assisted local anaesthesia for endoscopic dacryocystorhinostomy. Clin Experiment Ophthalmol. 2007;35:256-261.

23. Smith W, Merkonidis C, Draper M, Yung M. Endoscopic dacryocystorhinostomy in warfarinized patients. Am J Otolaryngol Head Neck Med Surg. 2006;27:327-329.

24. Boush GA, Lemke BN, Dortzbach RK. Results of endonasal laserassisted dacryocystorhinostomy. Ophthalmology. 1994;101:955.

25. Hartikainen J, Antila J, Varpula M, Puukka P, Seppa H, Grenman R. Prospective randomised comparison of endonasal endoscopic dacryocystorhinostomy and external dacryocystorhinostomy. Laryngoscope. 1998;108:1861-1866.

26. Onerci M. Dacryocystorhinostomy. Diagnosis and treatment of nasolacrimal canal obstructions. Rhinology. 2002;40(2):49-65.

27. Unlu HH, Toprak B, Aslan A, Guler C. Comparison of surgical outcomes in primary endoscopic dacryocystorhinostomy with and without silicone intubation. Ann Otol Rhinol Laryngol. 2002;111:704-709.
28. Leong SC, Macewen CJ, White PS, A systematic review of outcomes after dacryocystorhinostomy in adults. Am J Rhinol Allergy. 2010;24(1): $81-90$.

29. Sharma BR. Non endoscopic endonasal dacryocystorhinostomy versus external Dacryocystorhinostomy. Kathmandu Univ Med J. 2008;6(24): $437-442$.

30. Jin HR, Yeon JY, Choi MY. Endoscopic dacryocystorhinostomy: creation of a large marsupialized lacrimal sac. J Korean Med Sci. 2006; 21(4):719-723.

31. Nussbaumer M, Schreiber S, Yung MW. Concomitant nasal procedures in endoscopic dacryocystorhinostomy. J Laryngol Otol. 2004;118: 267-269.

32. Moore WM, Bentley CR, Olver JM. Functional and anatomic results after two types of endoscopic endonasal dacryocystorhinostomy: surgical and holmium laser. Ophthalmology. 2002;109:1575-1582.

33. Zilelioglu G, Tekeli O, Ugurba SH, Akiner M, Akturk T, Anadolu Y. Results of endoscopic endonasalnon-laser dacryocystorhinostomy. Doc Ophthalmol. 2002;105:57-62.

34. Fayet B, Racy E, Assouline M. Systematic unciformectomy for a standardized endonasal dacryocystorhinostomy. Ophthalmology. 2002;109: $530-536$.

35. Onerci M, Orhan M, Ogretmenoğlu O, Irkec M. Long-term results and reasons for failure of intranasal endoscopic dacryocystorhinostomy. Acta Otolaryngol. 2000;120(2):319-322.

36. Watters GWR, Whittet HB, Shun-shin GA, Milford CA, Endoscopic transnasal dacryocystorhinostomy -long-term results. Minimally Invasive Therapy and Allied Technologies. 1996;5(6):505-510.

37. Pandya VB, Lee S, Benger R, et al. External dacryocystorhinostomy: assessing factors that influence outcome. Orbit. 2010;29(5) 291-297.

38. Delaney YM, Khooshabeh R. External dacryocystorhinostomy for the treatment of acquired partial nasolacrimal obstruction in adults. Br J Ophthalmol. 2002;86:533-553.

39. Feretis M, Newton JR, Ram B. Comparison of external and endonasal dacryocystorhinostomy. J Laryngol Otol. 2009;123(3):315-319.

40. Leong SC, Karkos PD, Burgess P, Halliwell M, Hampal S. A comparison of outcomes between nonlaser endoscopic endonasal and external dacryocystorhinostomy: single-center experience and a review of British trends. Am J Otolaryngol. 2010;31(1):32-37.

41. Maini S, Raghava N, Youngs R et al. Endoscopic endonasal laser versus endonasal surgical dacryocystorhinostomy for epiphora due to nasolacrimal duct obstruction: prospective, randomised, controlled trial. J Laryngol Otol. 2007;121(12):1170-1176.
Clinical Ophthalmology

\section{Publish your work in this journal}

Clinical Ophthalmology is an international, peer-reviewed journal covering all subspecialties within ophthalmology. Key topics include: Optometry; Visual science; Pharmacology and drug therapy in eye diseases; Basic Sciences; Primary and Secondary eye care; Patient Safety and Quality of Care Improvements. This journal is indexed on Submit your manuscript here: http://www.dovepress.com/clinical-ophthalmology-journal

\section{Dovepress}

PubMed Central and CAS, and is the official journal of The Society of Clinical Ophthalmology (SCO). The manuscript management system is completely online and includes a very quick and fair peer-review system, which is all easy to use. Visit http://www.dovepress.com/ testimonials.php to read real quotes from published authors. 